\title{
Risk Factors and Outcomes of Early Pulmonary Hypertension in Preterm Neonate
}

\author{
S.A.Dabour ${ }^{1}$, E.H.Asser ${ }^{1}$ and Abeer.ES.Hamed ${ }^{2}$
}

${ }^{1}$ Pediatric, Dept., Faculty of Medicine, Benha Univ., Benha, Egypt

${ }^{2}$ National Heart Institute, GOTHI, Egypt

E-Mail:amira@gmail.com

\begin{abstract}
Early onset pulmonary arterial hypertension in preterm is not uncommon and is associated with bronchopulmonary dysplasia and severe intraventricular hemorrhage. Inhaled nitric oxide was used to treat in majority of cases with good response and survival is high. Approximately 8-23\% of premature infants develop pulmonary hypertension (PH), and this diagnosis confers a higher possibility of mortality. As a result, professional societies recommend $\mathrm{PH}$ screening in premature infants. However, the risk factors for and the outcomes of $\mathrm{PH}$ may differ depending on the timing of its diagnosis, and little evidence is available to determine at-risk infants in the referral neonatal population. Aim of this work: was to examine the risk factors and neonatal outcomes of early onset PAH (EOPAH) diagnosed in the first 2 weeks of age in preterm infants in a large perinatal center. Methods: This study was conducted on sequentially admitted preterm neonates in Benha children Hospital (130). A prospective observational study on neonates were admitted to neonatal intensive care unit allover 6 months since 1st of July to the end of December 2019. All the neonates were evaluated by echocardiogram between 72 hours and 14 days for early detection of pulmonary hypertension. Results: Regarding Early pulmonary arterial hypertension, Cases with early pulmonary arterial hypertension were $30(23.1 \%)$ and Cases without early pulmonary arterial hypertension were 100 (76.9\%). mean value of weight among Cases with early pulmonary arterial hypertension was lower than among Cases without early pulmonary arterial hypertension $(1.68,2.07) \mathrm{p}$ value $=0.000$, we found that, regarding Maternal risk factors among cases with early pulmonary arterial hypertension, BA were 2 (6.7\%), over weight mother was $3(10 \%)$, hypertension was $1(3.3 \%)$, prom was $1(3.3 \%)$, irrelevant was $21(70 \%)$ and Smoker mother were 2 (6.7\%). regarding outcome, the percentage of die was higher among Cases with early pulmonary arterial hypertension than Cases without early pulmonary arterial hypertension $(26.7 \%, 2 \%) . \mathrm{P}$ value $=0.000$.regarding fundus examination results was abnormal was $3(10 \%)$ among cases with early pulmonary arterial hypertension. Regarding degree of pulmonary hypertension mild was 19 (63.3\%), moderate was $10(33.3 \%)$ and sever was 1 (3.3\%). Conclusion: Our study shows that clinically significant EOPAH is present in $23.1 \%$ of preterm infants of less than 36 weeks GA. Our results shows that lower birth weights are associated with pulmonary hypertension. The mortality rate among the infants who affected with pulmonary hypertension was high. Regarding O2 Therapy, the percentage of Invasive MV was higher among Cases with early pulmonary arterial hypertension Hearing and fundus impairment occurred among cases with early pulmonary arterial hypertension.
\end{abstract}

Keywords: Risk Factors, Outcomes, Early Pulmonary Hypertension, preterm Neonate.

\section{Introduction}

Early onset pulmonary arterial hypertension in preterm is not uncommon and is associated with bronchopulmonary dysplasia and severe intraventricular hemorrhage. Inhaled nitric oxide was used to treat in majority of cases with good response and survival is high [1].

Approximately $8-23 \%$ of premature infants develop pulmonary hypertension, and this diagnosis confers a higher possibility of mortality. As a result, professional societies recommend pulmonary hypertension screening in premature infants. However, the risk factors for and the outcomes of pulmonary hypertension may differ depending on the timing of its diagnosis, and little evidence is available to determine at-risk infants in the referral neonatal population [2].

2.1 Persistent pulmonary hypertension of the newborn can be characterized as one of four types.

1. Maladaptation: Secondary to lung parenchymal diseases such as meconium aspiration syndrome.

2. Maldevelopment: Lung with normal parenchyma and remodeled pulmonary vasculature, also known as idiopathic persistent pulmonary hypertension of the newborn.
3. Underdevelopment: Hypoplastic vasculature as seen in congenital diaphragmatic hernia and other causes of pulmonary hypoplasia (oligohydramnios secondary to Potter's Syndrome, renal disease or chronic leakage of amniotic fluid)

4. Intrinsic obstruction: high viscosity due to polycythemia resulting in intravascular obstruction and elevated pulmonary vascular resistance.

Echocardiography is gold standard to confirm the diagnosis, and to monitor the efficacy of specific therapeutic interventions [3]. Persistent pulmonary hypertension of the newborn is a syndrome associated with significant long term morbidity, irrespective of the treatment modality. These infants suffer from long-term consequences such as neuro developmental, cognitive and hearing abnormalities [4]. Thus, it is essential to provide long-term multidisciplinary follow-up after discharge.

The presence of early pulmonary hypertension on echocardiogram between 72 hours and 14 days of age was associated with decreased in-hospital survival and worse pulmonary outcomes. This population represents a group of infants who permit further investigation to improve outcomes [5]. 
The aim of this work was to examine the risk factors and neonatal outcomes of early onset pulmonary arterial hypertension diagnosed in the first 2 weeks of age in preterm infants in a large perinatal center (Benha Children Hospital and Benha Teaching Hospital).

\section{Patients and Methods}

This study was conducted on sequentially admitted preterm neonates (130) in Benha children Hospital and Benha teaching Hospital. An observational prospective study on neonates were admitted to neonatal intensive care unit allover 6 months since 1st of July to the end of December 2019.

All the neonates were evaluated by echocardiogram between 72 hours and 14 days for early detection of pulmonary hypertension.

130 preterm neonates was classified into Cases with early pulmonary arterial hypertension and Cases without early pulmonary arterial hypertension.

\subsection{Inclusion criteria}

Preterm neonates $\leq 36$ weeks who were admitted to NICU of Benha Children Hospital during the 6 months.

\subsection{Exclusion criteria}

All the full term neonates or neonates with multiple congenital anomalies were excluded from the study.

\subsection{Methods}

During admission every neonate was subjected to:

- Full medical history (name- age- gender -weight duration of admission). Full medical history for mother (to detect maternal risk factor).

- Laboratory investigations:

- Complete blood count (CBC) at birth for all cases. CBC was done for all samples using Sysmex KX$21 \mathrm{~N}$ for red blood cell (RBC) count, haemoglobin level, hematocrit value, WBC count and platelet count. C- reactive protein (CRP) at birth for all cases. Quantitative CRP:

- CRP was measured using human ELISA (sandwitch technique) kits provided by Quantiqine, R\&D Systems China Co., Ltd. (catalog No. DCRP00).

- 3. Transthoracic echocardiography is used to estimate PAP from continuous wave Doppler measurements. The estimation of systolic PAP is based on the peak tricuspid regurgitation velocity (TRV) taking into account right atrial pressure (RAP) as described by the simplified Bernoulli equation.

RAP can be estimated by echocardiography based on the diameter and respiratory variation in diameter of the inferior vena cava (IVC): an IVC diameter $<2.1$ $\mathrm{cm}$ that collapses $>50 \%$ with a sniff suggests a normal RA pressure of $3 \mathrm{mmHg}$ (range $0-5 \mathrm{mmHg}$ ), whereas an IVC diameter $>2.1 \mathrm{~cm}$ that collapses $<50 \%$ with a sniff or $<20 \%$ on quiet inspiration suggests a high RA pressure of $15 \mathrm{mmHg}$ (range 10-20 $\mathrm{mmHg}$ ). In scenarios in which the IVC diameter and collapse do not fit this paradigm, an intermediate value of $8 \mathrm{mmHg}$ (range 5-10 $\mathrm{mmHg}$ ) may be used. The EACVI recommends such an approach rather than using a fixed value of 5 or 10 $\mathrm{mmHg}$ for PA systolic pressure (PASP) estimations. However, given the inaccuracies of RAP estimation and the amplification of measurement errors by using derived variables, we recommend using the continuous wave Doppler measurement of peak TRV (and not the estimated PASP) as the main variable for assigning the echocardiographic probability of PH. signs are proposed in addition to criteria based on TRV. These signs provide assessment of the RV size and pressure overload, the pattern of blood flow velocity out of the RV, the diameter of the PA and an estimate of RAP.

\subsection{Grading of PAH: Ahmed et al., [6] \\ - Mild - 25-40 mmHg \\ - Moderate - 40-60 mmHg \\ - Severe - >60 mmHg.}

Cranial ultrasound \& other radiological investigations was indicated in clinical assessment.

After discharge every neonate was subjected to:

- Hearing assessment.

- Retinal examination.

\subsection{Ethical Consideration}

Ethical permission for the study was obtained from the parents who were fully informed about all study procedures and their consent was obtained prior to the children enrollment in the study. This study was approved by the ethical committee of the faculty of Medicine, Benha University Hospitals.

\subsection{Statistical Analysis}

Data analysis was performed using the software SPSS (Statistical Package for the Social Sciences) version 24. Quantitative variables were described using their means and standard deviations. Categorical variables were described using their absolute frequencies and were compared using Chi square test and fisher exact test when appropriate. Kolmogorov-Smirnov (distribution-type) tests were used to verify assumptions for use in parametric tests. To compare continuous quantitative data of two groups, Mann whitney test (for non-normally distributed data) and independent sample $t$ test (for normally distributed data) were used. The level statistical significance was set at $5 \%(\mathrm{P}<0.05)$.

\section{Results}

This table shows that the percentage of female were $49(37.7 \%)$ and male were $81(62.3 \%)$ Table (1).

Regarding Early pulmonary arterial hypertension, Cases with early pulmonary arterial hypertension were $30(23.1 \%)$ and Cases without early pulmonary arterial hypertension were 100 (76.9\%) Table (2).

There was no statistically significant difference between Cases with early pulmonary arterial hypertension and Cases without early pulmonary arterial hypertension regarding sex Table (3).

There was no statistically significant difference between Cases with early pulmonary arterial hypertension and Cases without early pulmonary arterial hypertension regarding mode of delivery Table (4). 
Mean value of weight among Cases with early pulmonary arterial hypertension was lower than among Cases without early pulmonary arterial hypertension $(1.68,2.07) \mathrm{p}$ value $=0.000$ Table $(5)$.

Regarding Maternal risk factors, BA were 2 (6.7\%), over weight mother was $3(10 \%)$, hypertension was 1 $(3.3 \%)$, prom was $1(3.3 \%)$, irrelevant was $21(70 \%)$ and Smoker mother were $2(6.7 \%)$ Table (6).

Mean value of CRP among Cases with early pulmonary arterial hypertension was higher than among Cases without early pulmonary arterial hypertension $(10.40,5.82) \mathrm{p}$ value $=0.000$ Table (7)

Regarding $\mathrm{O} 2$ Therapy, the percentage of Invaive MV was higher among Cases with early pulmonary arterial hypertension than Cases without early pulmonary arterial hypertension $(66.7 \%, .0 \%)$. $\mathrm{P}$ value $=0.000$ Table (8).

Regarding outcome, the percentage of die was higher among Cases with early pulmonary arterial hypertension than Cases without early pulmonary arterial hypertension $(26.7 \%, 2 \%)$. P value $=0.000$ Table (9).

Abnormal ABR was 1 (3.3\%) among cases with early pulmonary arterial hypertension Table (10).

Regarding fundus examination results was abnormal was 3 (10\%) among cases with early pulmonary arterial hypertension Table (11).

Table (1) Sex among the studied cases.

\begin{tabular}{llcc}
\hline & & No. & \% \\
\hline \multirow{2}{*}{ Sex } & Female & 49 & 37.7 \\
& Male & 81 & 62.3 \\
\hline
\end{tabular}

Table (2) Early pulmonary arterial hypertension among the studied cases.

\begin{tabular}{llcc}
\hline & & No. & $\%$ \\
\hline & $\begin{array}{l}\text { Cases with early } \\
\text { pulmonary arterial } \\
\text { hypertension }\end{array}$ & 30 & 23.1 \\
$\begin{array}{l}\text { Early pulmonary } \\
\text { arterial hypertension }\end{array}$ & $\begin{array}{l}\text { Cases without early } \\
\text { pulmonary arterial } \\
\text { hypertension }\end{array}$ & 100 & 76.9 \\
\hline
\end{tabular}

Table (3) Comparison between Cases with early pulmonary arterial hypertension and Cases without early pulmonary arterial hypertension regarding sex.

\begin{tabular}{|c|c|c|c|c|c|c|}
\hline & & & $\begin{array}{c}\text { Cases with early } \\
\text { pulmonary arterial } \\
\text { hypertension }\end{array}$ & $\begin{array}{c}\text { Cases without early } \\
\text { pulmonary arterial } \\
\text { hypertension }\end{array}$ & $\mathrm{X} 2$ & P. value \\
\hline Sex & $\begin{array}{l}\text { Female } \\
\text { Male }\end{array}$ & $\begin{array}{l}\text { No. } \\
\% \\
\text { No. } \\
\%\end{array}$ & $\begin{array}{c}13 \\
43.3 \% \\
17 \\
56.7 \%\end{array}$ & $\begin{array}{c}36 \\
36.0 \% \\
64 \\
64.0 \%\end{array}$ & .528 & 0.467 \\
\hline
\end{tabular}

Table (4) Comparison between Cases with early pulmonary arterial hypertension and Cases without early pulmonary arterial hypertension regarding mode of delivery.

\begin{tabular}{lllcccc}
\hline & & & $\begin{array}{c}\text { Cases with early } \\
\text { pulmonary arterial } \\
\text { hypertension }\end{array}$ & $\begin{array}{c}\text { Cases without early } \\
\text { pulmonary arterial } \\
\text { hypertension }\end{array}$ & X2 & P. value \\
\hline \multirow{3}{*}{ mode of delivery } & CS & $\begin{array}{l}\text { No. } \\
\text { \% }\end{array}$ & 24 & 75 & .318 & 0.573 \\
& NVD & No. & $80.0 \%$ & 6 & $75.0 \%$ & \\
\hline
\end{tabular}

Caesarean section (CS) - normal vaginal delivery (NVD)

Table (5) Comparison between Cases with early pulmonary arterial hypertension and Cases without early pulmonary arterial hypertension regarding weight.

\begin{tabular}{cccc}
$\begin{array}{c}\text { Cases with early } \\
\text { pulmonary arterial } \\
\text { hypertension }\end{array}$ & $\begin{array}{c}\text { Cases without early } \\
\text { pulmonary arterial } \\
\text { hypertension }\end{array}$ & t.test & P. value \\
\hline
\end{tabular}




\begin{tabular}{llllll}
\hline Weight & Mean \pm SD & $1.68 \pm .344$ & $2.07 \pm .372$ & -5.196 & 0.000 \\
\hline
\end{tabular}

Table (6) Maternal risk factors among Cases with early pulmonary arterial hypertension.

\begin{tabular}{|c|c|c|c|}
\hline & & & Cases with early pulmonary arterial hypertension \\
\hline & BA & No. & 2 \\
\hline & & $\%$ & $6.7 \%$ \\
\hline & Over weight mother & No. & 3 \\
\hline & & $\%$ & $10 \%$ \\
\hline & hypertension & No. & 1 \\
\hline Matornal ricl foctor & & $\%$ & $3.3 \%$ \\
\hline vaternal risk ractor & Prom & No. & 1 \\
\hline & & $\%$ & $3.3 \%$ \\
\hline & Irrelevant & No. & 21 \\
\hline & & $\%$ & $70 \%$ \\
\hline & Smoker mother & No. & 2 \\
\hline & & $\%$ & $6.7 \%$ \\
\hline
\end{tabular}

Bronchial asthma(BA)

Table (7) Comparison between Cases with early pulmonary arterial hypertension and Cases without early pulmonary arterial hypertension regarding CRP.

\begin{tabular}{lccccc}
\hline & & $\begin{array}{c}\text { Cases with early pulmonary } \\
\text { arterial hypertension }\end{array}$ & $\begin{array}{c}\text { Cases without early pulmonary } \\
\text { arterial hypertension }\end{array}$ & t.test & P. value \\
\hline CRP & Mean $\mathbf{E}$ SD & $10.40 \pm 6.85$ & $5.82 \pm 2.69$ & 5.458 & 0.000 \\
\hline
\end{tabular}

C-reactive protein (CRP)

Table (8) Comparison between Cases with early pulmonary arterial hypertension and Cases without early pulmonary arterial hypertension regarding $\mathrm{O} 2$ Therapy.

\begin{tabular}{|c|c|c|c|c|c|c|}
\hline & & & $\begin{array}{c}\text { Cases with early } \\
\text { pulmonary arterial } \\
\text { hypertension }\end{array}$ & $\begin{array}{c}\text { Cases without early } \\
\text { pulmonary arterial } \\
\text { hypertension }\end{array}$ & $\mathbf{X} 2$ & P. value \\
\hline \multirow{6}{*}{ O2 Therapy } & Invasive MV & No. & 20 & 0 & \multirow[t]{6}{*}{ FE } & \multirow[t]{6}{*}{0.000} \\
\hline & \multirow{3}{*}{ NIV CPAP } & $\%$ & $66.7 \%$ & $.0 \%$ & & \\
\hline & & No. & 10 & 0 & & \\
\hline & & $\%$ & $33.3 \%$ & $.0 \%$ & & \\
\hline & \multirow{2}{*}{$\begin{array}{l}\text { O2 Support (nasal } \\
\text { or mask) }\end{array}$} & No. & 0 & 100 & & \\
\hline & & $\%$ & $.0 \%$ & $100.0 \%$ & & \\
\hline
\end{tabular}
(CPAP)

Oxygen (O2) - mechanical ventilation (MV) - Non-invasive ventilation (NIV) - continuous positive airway pressure

Table (9) Comparison between Cases with early pulmonary arterial hypertension and Cases without early pulmonary arterial hypertension regarding outcome.

\begin{tabular}{|c|l|l|c|c|c|c|}
\hline \multicolumn{2}{|c|}{} & \multicolumn{1}{|c|}{$\begin{array}{c}\text { Cases with early } \\
\text { pulmonary arterial } \\
\text { hypertension }\end{array}$} & $\begin{array}{c}\text { Cases without early } \\
\text { pulmonary arterial } \\
\text { hypertension }\end{array}$ & \multirow{2}{*}{ X2 } & P. value \\
\hline \multirow{3}{*}{ outcome } & \multirow{2}{*}{ Die } & No. & $\%$ & 2 & 16.453 & 0.000 \\
\cline { 3 - 6 } & \multirow{2}{*}{ Discharged } & No. & $26.7 \%$ & 98 & \\
\cline { 3 - 6 } & & $\%$ & $73.3 \%$ & $98 \%$ & \\
\hline
\end{tabular}

Table (10) Hearing assessment among Cases with early pulmonary arterial hypertension.

\begin{tabular}{lllc}
\hline & & & Cases with early pulmonary arterial hypertension \\
\hline & Abnormal & No. & 1 \\
Hearing assessment & ABR & $\%$ & $3.3 \%$ \\
& normal ABR & No. & 29 \\
& & $\%$ & $96.7 \%$ \\
\hline
\end{tabular}


Auditory Brainstem Response (ABR)

Table (11) fundus examination results among Cases with early pulmonary arterial hypertension.

\begin{tabular}{|c|c|c|c|}
\hline & & & Cases with early pulmonary arterial hypertension \\
\hline \multirow{4}{*}{ fundus examination results } & normal fundus & No. & 27 \\
\hline & & $\%$ & $90 \%$ \\
\hline & abnormal & No. & 3 \\
\hline & & $\%$ & $10 \%$ \\
\hline
\end{tabular}

\section{Discussion}

In the current study, regarding early pulmonary arterial hypertension, Cases with early pulmonary arterial hypertension were $30(23.1 \%)$ and Cases without early pulmonary arterial hypertension were 100 (76.9\%).

This was in accordance with Ahmed et al., [6] who found a total number of neonates screened were 41, of which 18 (43.9\%) cases had PAH. In Mourani et al., [7] reported the overall incidence of $\mathrm{PAH}$ was $42 \%$.

In a recent study, the incidence of EOPAH was $22.7 \%$ [5].

In the present work, we found that, there was no statistically significant difference between Cases with early pulmonary arterial hypertension and Cases without early pulmonary arterial hypertension regarding sex.

This contradict with the finding of the study of Barst et al. [8] who found that the female to male ratio was $2 / 1$.

Also was in disagreement with Hernandez-Dias et al. [9] who conducted a study on 377 infants with PPHN and found that a male gender is a risk factor with increased number of affected males 239 (63.4\%) when compared to number of affected females 138 (36.6\%).

This study showed that, there was no statistically significant difference between Cases with early pulmonary arterial hypertension and Cases without early pulmonary arterial hypertension regarding mode of delivery $(80 \%, 75 \%$ respectively).

This comes in agreement with Abdel Mohsen and Amin, [10] who aimed to estimate the possible risk factors and assess the outcome of Persistent pulmonary hypertension of the newborn (PPHN). They found that, The majority of neonates were delivered by cesarean section (62.5\% of cases) due to prenatal problems in agreement with Previous studies had reported cesarean section delivery was associated with a high incidence of respiratory distress syndrome and PPHN [11] .

This study showed that, mean value of weight among Cases with early pulmonary arterial hypertension was lower than among Cases without early pulmonary arterial hypertension $(1.68,2.07) \mathrm{p}$ value $=0.000$

In the present work, we found that, regarding Maternal risk factors among cases with early pulmonary arterial hypertension, BA were $2(6.7 \%)$, over weight mother was $3(10 \%)$, hypertension was $1(3.3 \%)$, prom was $1(3.3 \%)$, irrelevant was $21(70 \%)$ and Smoker mother were $2(6.7 \%)$.

In agreement with study by Hernandez-Dias et al. [9] found 61(16.2\%) mothers having asthma out of 377 cases of PPHN.
Also study by Razzaq et al. [12] found that $3.6 \%$ of PHN patients have history of hypertension in the mother.

Similar result was found in Bakheet et al., [13] who found that one out of 13 neonates $(7.7 \%)$ with the history of pregnancy induced hypertension in mother had PAH at first screening.

In our study we did not find any case of PAH with Diabetes as a risk factor.

Other studies by Hernandez-Dias et al. [9], Razzaq et al. [12], Bakheet et al., [13] showed diabetes (IDM) as a risk factor for PHN with a prevalence of $25.9 \%, 9.8 \%$, $5.1 \%$ DM in PHN cases respectively.

Similarly we did not find any case of PAH with history of drug intake (e.g.SSRI) and UTI in the mothers but study by Hernandez-Dias et al. [9] showed that $3.75 \%$ \& $9.0 \%$ cases respectively had such history in the mother of PPHN cases.

In our study no cases of oligohydroamnios were screened as a risk factor for PAH.

Study by Kumar et al., [14] on 61 preterm infants having PHN found $18 \%$ cases had Oligohydroamnios in the mother.

In the present work, regarding diagnosis, RD due to pulmonary hypertension were $30(23.1 \%)$ and RD due to other causes (congenital pneumonia, RDS, sepsis) were $100(76.9 \%)$.

In harmony with Harerimana et al., [15] study, the most common underlying diseases in PPHN were MAS, pneumonia and RDS.

MAS has repeatedly been reported as the most common lung parenchymal disease resulting in PPHN, followed by idiopathic PPHN and pneumonia or RDS. $[16,17]$ Our results were similar to those reported in previous studies [10].

This study showed that, regarding outcome, the percentage of die was higher among Cases with early pulmonary arterial hypertension than Cases without early pulmonary arterial hypertension $(26.7 \%, 2 \%)$. $\mathrm{P}$ value= 0.000

In agreement with the study of Ather et al., [18] who found that, the mortality rate among the infants who affected with pulmonary hypertension was $20 \%$.

These results were contradict with study carried out by Seth et al., [1] who aimed to examine the risk factors and neonatal outcomes of early onset PAH (EOPAH). They found that, the overall mortality rate was not significantly different between two groups (13.3\% vs. $8 \%)$. 
In the present work, Regarding $\mathrm{O}^{2}$ Therapy, the percentage of Invaive MV was higher among Cases with early pulmonary arterial hypertension than Cases without early pulmonary arterial hypertension $(66.7 \%, .0 \%)$. P value $=0.000$

Our findings are consistent with reports that assisted ventilation constitutes the mainstay of PPHN treatment [19].

The infants with PPHN who survive and are discharged from the NICU have hearing abnormalities. Lipkin et al., [20] Thus, it is essential to provide longterm multidisciplinary follow-up after discharge.

This study showed that, abnormal ABR was 1 (3.3\%) among cases with early pulmonary arterial hypertension.

Konduri et al. [4] noted hearing impairment in approximately $23 \%$.

This study showed that, regarding fundus examination results was abnormal was $3(10 \%)$ among cases with early pulmonary arterial hypertension.

These findings were comparable with the result of study made by Seth et al., [1] who found that, abnormal fundus examination was (11\%) among cases with early pulmonary arterial hypertension.

\section{Conclusion}

- Our study shows that clinically significant EOPAH is present in $23.1 \%$ of preterm infants of less than 36 weeks GA.

- Our results shows that lower birth weights are associated with pulmonary hypertension.

- The mortality rate among the infants who affected with pulmonary hypertension was high.

- Regarding O2 Therapy, the percentage of Invasive MV was higher among Cases with early pulmonary arterial hypertension

- Hearing and fundus impairment occurred among cases with early pulmonary arterial hypertension.

\section{References}

[1] SA.Seth, AS. Soraisham, A.Harabor . Risk factors and outcomes of early pulmonary hypertension in preterm infant $\mathbf{J}$ Matern Fetal Neonatal Med.vol. 31(23),pp.3147-3152. ,2018.

[2] S.Vyas-Read, U.Kanaan, P.Shankar. Early characteristics of infants with pulmonary hypertension in a referral neonatal intensive care unit. BMC Pediatr. 2017 Jul 11.vol.17(1),pp.163,2017.

[3] M.D'Alto, E.Romeo, P.Argiento. Pulmonary arterial hypertension: the key role of echocardiography. Echocardiography.vol.32 Suppl 1,pp.S23-37,2015.

[4] GG. Konduri, B.Vohr, C.Robertson. Early inhaled nitric oxide therapy for term and nearterm newborn infants with hypoxic respiratory failure: neurodevelopmental follow-up. J Pediatr.vol.150(3),pp.235-240, 240 e231,2007.

[5] A.Berenz, JE.Vergales, JR.Swanson. Evidence of Early Pulmonary Hypertension Is Associated with Increased Mortality in Very Low Birth Weight Infants. Am J Perinatol. 2017 Jul.vol.34(8),pp.801-807,2017.

[6] T.Ahmed, S.Abqari, T.Shahab. Prevalence and outcome of pulmonary arterial hypertension in newborns with perinatal asphyxia. J Clin Neonatol.vol.7,pp.63-6,2018.

[7] PM.Mourani, MK.Sontag, A.Younoszai. Early pulmonary vascular disease in preterm infants at risk for bronchopulmonary dysplasia. Am J Respir Crit Care Med.vol.191,pp.87-95,2015.

[8] RJ. Barst, MD.McGoon, CG.Elliott. Survival in childhood pulmonary arterial hypertension: insights from the registry to evaluate early and long-term pulmonary arterial hyper- tension disease management. Circulation.vol. 125,pp.113-122,2012.

[9] S.Hernández-Díaz, LJ.Van Marter, MM.Werler. Risk factors for persistent pulmonary hypertension of the newborn. Pediatrics.vol.120,pp.e272-82,2007.

[10] AH.Abdel Mohsen, AS. Amin. Risk factors and outcomes of persistent pulmonary hypertension of the newborn in neonatal intensive care unit of Al-Minya University Hospital in Egypt. J Clin Neonatol.vol. 2(2),pp.78-82,2013.

[11]OR.de Araujo, Andrea de Cdssia Stefano, Vanessa Aparecida. Cesarean deliveries and other risks for persistent pulmonary hypertension of the newborn. Bras Ter lntensiva.vol. 20,pp.394-7,2008.

[12] A.Razzaq, AI .Quddusi, N.Nizami. Risk factors and mortality among newborns with persistent pulmonary hypertension. Pakistan journal of medical sciences.vol. 29(5),pp.1099. ,2013.

[13]MA.Bakheet, KA.Metwalley, AS.AbdelRaheem. Evaluation of persistent pulmonary hypertension of the newborn (PPHN) in Upper Egypt. Egypt Pediatr Assoc Gazette.vol.61,pp.96-9, 2013.

[14] VH.Kumar, AA. Hutchison, S.Lakshminrusimha. Characteristics of pulmonary hypertension in preterm neonates. $\mathbf{J}$ Perinatol.vol.27(4),pp.214-219,2007.

[15]I.Harerimana, D. E.Ballot, P.Cooper. Retrospective review of neonates with persistent pulmonary hypertension of the newborn at Charlotte Maxeke Johannesburg Academic Hospital. South African Journal of Child Health.vol. 12(1),pp. 29,2018.

[16] S.Lakshminrushimha, VH.Kumar. Diseases of pulmonary circulation. In: Fuhrman BP, Zimmerman JJ, eds. Pediatric Critical Care. 4th ed. Philadelphia: Elsevier.vol.5,pp. 638-645. ,2011.

[17] C.Teixeira-Mendonc, T.Henriques-Coelhob. Pathophysiology of pulmonary hypertension in newborns: Therapeutic indications. Rev Port Cardiol.vol. 32(12),pp.1005-1012,2013. 
[18]R. Ather, Q. Ahmed and N.Nabila. Risk factors and mortality rate among newborns with persistent pulmonary hypertension. Sep-Oct.vol. 29(5),pp. 1099:1100. Park J. Med. Sci. ,2013.

[19]P.Bendapudi, S.Barr. Diagnosis and management of pulmonary hypertension of the newborn. Paediatr Child Healt.vol. 24(1),pp.12$16,2013$.

[20] PH.Lipkin, D.Davidson, L.Spivak. Neurodevelopmental and medical outcomes of persistent pulmonary hypertension in term newborns treated with nitric oxide. J Pediatr.vol.140(3),pp.306-310,2002. 